\title{
Does the Meeting Centres Support Programme reduce unmet care needs of community-dwelling older people with dementia? A controlled, 6-month follow-up Polish study
}

This article was published in the following Dove Medical Press journal:

Clinical Interventions in Aging

Justyna Mazurek'

Dorota Szcześniak ${ }^{2}$

Katarzyna Małgorzata Lion ${ }^{2}$

Rose-Marie Dröes ${ }^{3}$

Maciej Karczewski ${ }^{4}$

Joanna Rymaszewska²

'Department and Division of Medical Rehabilitation, Wroclaw

Medical University, Wrocław, Poland;

${ }^{2}$ Department of Psychiatry, Wroclaw

Medical University, Wroclaw, Poland;

${ }^{3}$ Department of Psychiatry, VU

University Medical Centre/GGZ in

Geest, Amsterdam, the Netherlands;

${ }^{4}$ Department of Mathematics,

Wroclaw University of Environmental

and Life Sciences, Wroclaw, Poland
Correspondence: Justyna Mazurek Department and Division of Medical Rehabilitation, Wroclaw Medical University, Borowska 213,

Wroclaw, Poland

Tel +48695I80984

Email justyna.mazurek@umed.wroc.pl
Introduction: In Poland we lack a multidisciplinary and coordinated system of care for people with dementia, which would take the form of an evidence-based pathway and the number of reports on the holistic approach to caring for people living with this diagnosis is very low.

Aim of the study: The aim of the study was to investigate whether the Meeting Centres Support Programme (MCSP) is effective in meeting the needs of older people with dementia. Participants and methods: This was done by comparing the experiences of people with dementia themselves and that of their carers at baseline and at follow-up, after 6 months of participation in MCSP or Usual Care (UC).

Results: The study included 47 people diagnosed with mild-to-moderate dementia ( $n=24$, MCSP group; $n=23$, UC control group) and 42 informal carers ( $n=22$, MCSP group; $n=20$, UC control group), all living in Wroclaw in Poland and involved in the European JPND-MEETINGDEM project. To assess cognitive functioning and severity of dementia, the Mini-Mental State Examination and Global Deterioration Scale were used. The needs were assessed using the Camberwell Assessment of Need for the Elderly. The most frequently reported unmet needs at baseline both by the persons with dementia and their carers included activities of daily living, psychological distress, and the need for company. Compared to the UC group the unmet needs were reduced considerably in the MCSP group providing convincing evidence that MCSP is effective in reducing unmet needs over a 6-month period.

Conclusion: MCSP may be regarded as a good example of comprehensive post-diagnostic support for patients with mild-to-moderate dementia as well as their informal carers.

Keywords: needs assessment, CANE, care management, health care, psychiatric services, social geriatrics, optimization, psychosocial care

\section{Introduction}

The significance of identifying the manners of promoting cost-efficient interventions, which can support people living with dementia in continuation of their independent life for as long as possible, is emphasized by the foreseen increase in both the number and proportion of elderly people diagnosed with dementia over the next 40 years. Conducting studies on this particular group is of great significance as it makes it possible to concentrate on the specific needs of persons who potentially are in the middle of the transition process from using solely informal care to a combination of both formal and informal care. ${ }^{1}$ Studies prove that there is a negative influence of cognitive impairment and dementia on the following aspects: dependency, institutionalization, mortality, 
as well as functional and psychological status. ${ }^{2}$ Huber et $\mathrm{al}^{3}$ lately suggested a reformulation of the definition of health formulated by the WHO, according to which the definition shall move from the current static formulation (a state of complete physical, mental, and social well-being) toward a more dynamic definition, which is based on the ability to adapt and self-manage physically, mentally, and socially, resulting in more or less physical, mental, and social health. The added value of the concept of social health lies in several core features: it is an umbrella for an array of concepts reflecting human capacities to participate in social life, such as reciprocity and dignity, and resilience. ${ }^{4,5}$ It seems to be especially important for the treatment of neurodegenerative diseases, such as dementia, when pharmacotherapeutical treatment is very limited. ${ }^{5}$

Needs assessment is the fundamental base for an effective social and health policy and the provision of needs-based interventions. Unmet needs can lead to a decreased quality of life and increased costs of care. ${ }^{6}$ It is important to be aware of the subjective needs of people with dementia and those of the informal carers and to meet them to improve their quality of life and to provide more appropriate person-centered care and support. ${ }^{7}$ Several systematic reviews demonstrate that the general mental health of people with dementia and carers can be improved by combined support programs and that admission to long-term care and institutionalization may be delayed. ${ }^{8-10}$

In Poland, there is a lack of a multidisciplinary, coordinated system of care for people with dementia in the form of an evidence-based structured pathway. ${ }^{11}$ The post-diagnostic support is very limited. There are no services to support carers emotionally, socially, or practically during the dementia journey. As a result, many people have unmet needs, especially socially and psychologically. ${ }^{9,11-13}$

This paper aims to present the results of a study conducted in the context of the MEETINGDEM project. This was a European Joint Programme Neurodegenerative Diseases Research funded project (2014-2017) aimed at adaptively implementing and evaluating the innovative Meeting Centres Support Programme (MCSP) for community-dwelling people with dementia and their carers in three European countries, that is, Poland, Italy, and the UK.9,14 The aim of the present study was to answer the question whether MCSP is effective in meeting the needs of older people with dementia in Poland. In addition, we explored and compared experienced unmet needs by people diagnosed with dementia and by their carers.

\section{The MCSP}

The concept of MCSP was developed 25 years ago in the Netherlands in collaboration with people living with dementia as well as their carers. ${ }^{15}$ The basis for MCSP is the theoretical framework of the Adaptation-Coping model according to which people with dementia and their informal caregivers need to cope with adaptive tasks, for example, dealing with disabilities, remaining social relationships, and maintaining an emotional balance and positive self-image. ${ }^{15,16}$ MCSP operates on the borders of social care, welfare, and health. Depending on the individual adaptation challenges and needs that people experience, the support focuses on (re-)activation, (re-)socialization, and/or improvement of the emotional functioning of the person with dementia, and information and practical, emotional, and social support for their informal carers. ${ }^{9,11,17}$

The MCSP is person-centered, that is, attuned to individual complex needs, abilities, and wishes, and focuses on helping people deal with the changes dementia brings to their life and supports them in living well with dementia. The Meeting Centre (MC) supports about 15 people with dementia plus their families in easily accessible community locations. The program integrates several support activities including cognitive stimulation, activity groups, music therapy, psychomotor therapy, family support groups, psychoeducation, and counseling. MCSP was shown to be effective for people with dementia and their carers in research and/or practice. ${ }^{9}$

There is a social club organized for the people with dementia (3 times per week). In the club people in question can take part in recreational activities and psychomotor therapy. As far as carers are concerned, there are psychoeducational meetings and discussion groups to participate in. Both groups can avail themselves of social activities, a weekly consultation hour and regular "center meetings" during which all participants, staff, as well as volunteers can share their experiences. The coordination of care services at home is also supported by the staff. ${ }^{9}$

The program is offered in accessible locations that facilitate social inclusiveness and community integration and promoting social participation. ${ }^{18,19}$ This makes them more attractive than institutional day care and makes it easier for people to use support from an early stage of the disease. Examples of activities that have developed in the centers spontaneously include playing billiards and having a drink with visitors at the coffee bar, painting together, and interacting with other generational groups using the same community facilities. In addition, family carers participate in activities in the community center. ${ }^{9}$

According to the conducted studies on the effectiveness of MCSP, compared to those using traditional day care after 7 months of participation in MCSP, people with dementia 
showed fewer behavioral and mood problems (less inactivity, unsocial and depressed behavior, and a higher self-esteem) and nursing home admission was delayed. ${ }^{15,18}$ People with dementia reported noticeable improvements regarding their self-esteem, as well as positive effect and the feeling of belonging after the period of 7 months of attending the MCs. There was a correlation noticed between increased levels of attendance and a significant reduction in symptoms of distressing behavior and greater feelings of support. ${ }^{15}$ This is the first study that focuses on the effectiveness of MCSP on unmet needs.

\section{Method Design}

A pre/post-test control group design was used for comparing outcomes for people with dementia and family carers attending the MCSP or a Usual Care (UC) at two time points, at baseline and after 6 months.

The study was approved by the Bioethical Commission at the Wroclaw Medical University (No KB-487/2015). This study was conducted in accordance with the Declaration of Helsinki.

\section{Participants and setting}

The main target group for the MCSP group were people with mild-to-moderately severe dementia, living at home, and having a carer prepared to participate as well. Exclusion criteria for the study were 1) severe dementia, 2) blind/deaf, 3) severe impairment in communication, 4) inability to give informed consent or assent in line with their level of cognitive abilities, 5) behavior disorders: severe aggression, behavior disturbing group work, lack of control or impulsive behavior, 6) physical disability preventing moving independently, 7) somatic ailments requiring pharmacologic stabilization, for example, poorly controlled diabetes, arterial hypertension. A sample of older people, over 65 years of age, of both sexes and diagnosed with dementia, with cognitive impairments confirmed by the Mini-Mental State Examination (MMSE) scores, and their informal carers were recruited for the study. The pilot MCSP was successfully implemented in two MCs in Wroclaw in Poland following a 12-month period of collaborative community engagement and preparatory work according to the Dutch stepwise implementation procedure. ${ }^{11,17}$

UC is the standard care provided in Poland. Since MCSP was introduced majority of people with dementia used outpatient clinic service with control medical visits every 3-4 months. In the presented study, persons with dementia from the UC group were admitted to general psychiatric day wards (Psychogeriatric Day Care units) for 3-4 months stay.
They all had an informal carer. Number of research participants is shown in Figure 1.

\section{Procedure}

The well-trained researcher provided all participants with the information about the study and asked them if they were willing to participate. Elderly people with dementia, who were subsequently admitted to the Department of Psychiatry in Wroclaw, were included in the study. Persons, who agreed to participate in the program, were included in the MCSP group. All the necessary measures to safeguard participants' anonymity and confidentiality of information were thoroughly followed. All participants gave their written consent for participation. Measures were taken at pretest (within the first month of starting to attend the MCs) and again after 6 months. People with dementia and their carers were interviewed during separate sessions. Each session took up to 2 hours (at baseline and at follow-up). Over time the following changes that could have influenced the results were recorded: illness, physical disability, significant changes in medication, as well as availing oneself of other types of support. There were also the reasons for dropout and life events noticed.

\section{Instruments}

Data of participants were collected via standardized clinical interviews that were performed by the trained staff. Background information on age, gender, education level, marital status, and relationship to the informal carer was collected for all participants.

To establish the severity of cognitive impairments and dementia, the $\mathrm{MMSE}^{20}$ and the Global Deterioration Scale $(G D S)^{21}$ were administered, respectively.

The MMSE contains 30 questions, which make a quantitative assessment of the cognitive function possible. The purpose of the MMSE is to test such skills as orientation to time and place, memory, attention and calculation, recall, naming objects, comprehension, reading, writing, and drawing. The person may maximally score 30 points. A result $<24$ points shall be regarded as cognitive impairment and it warrants further tests. The result of the test depends both on age and level of education (corrected result). In this study, the final MMSE score has been corrected by age and educational level.

The GDS makes it possible to assess the stages and severity of clinical dementia. There are seven stages distinguished: 1 - no cognitive decline, 2 - very mild cognitive decline, 3 - mild cognitive decline, 4 - moderate cognitive decline (mild dementia), 5 - moderately severe cognitive decline (moderate dementia), 6 - severe cognitive decline 


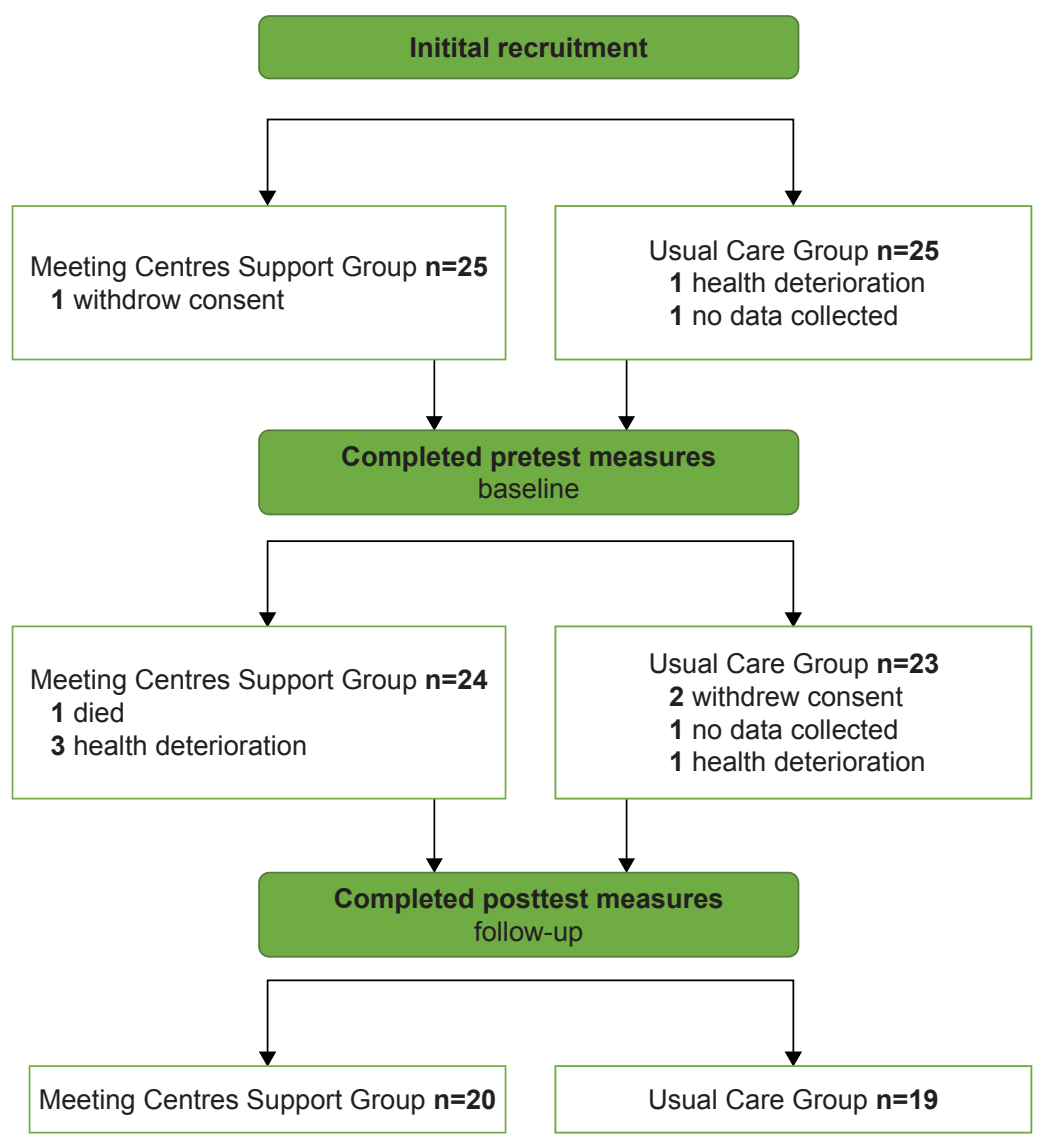

Figure I Recruitment strategy: numbers of research participants with dementia recruited to the Meeting Centres Support Group and the Usual Care Group in Poland.

(moderately severe dementia), and 7 - very severe cognitive decline (severe dementia).

For the needs assessment, the Camberwell Assessment of Need for the Elderly (CANE) was used, published by Reynolds et al in $2000,{ }^{22}$ and translated into Polish by Rymaszewska et al in 2008, showing good content, construct, and criterion validity. ${ }^{23}$ The CANE is the first tool designed to assess a wide range of needs of older people and can be used in persons who are mentally ill, and who reside in health and social care centers and in primary care facilities. Twenty-four needs areas are covered. With this instrument, needs are identified as being absent (score 0 ), met (score 1), or unmet (score 2). Each area is divided into five sections. The CANE assesses the physical needs (physical health, drugs, mobility/falls, self-care, incontinence, and eyesight/ hearing/communication), psychological needs (behavior, psychotic symptoms, alcohol, accidental and deliberate selfharm, psychological distress and memory), environmental needs (managing money, household activities, caring for another, and money), and social needs (company, intimate relationship, daytime activities, information on condition and abuse/neglect). In addition, formal (local stationary and semi-stationary health care or social care) and informal (family, friends, neighbors) care of the person is inventoried. The evaluation of the needs may be conducted by the following persons: elderly person themselves, interviewers/ researchers, health care professionals (eg, a physician or nurse), and the informal carers. Later on, these evaluations are compared. In this study, the person with dementia and the informal carer completed the CANE. In these analyses, we considered these two perspectives to make the best use of the available information.

Follow-up data were collected using the same measures 6 months after the baseline data collection point.

\section{Data analysis}

The differences in needs at baseline and follow-up in the research (MCSP) and control groups (UC) were tested by the Wilcoxon test. The analysis of the impact of the interventions (MCSP/UC) on the changes in needs (total, met, and unmet) was made with the use of generalized mixed models, taking into account differences in background characteristics 
between the MCSP and control group. The statistical analyses were carried out using the R statistical package (version 3.4.1). ${ }^{24}$ All tests were conducted two-sided with a statistical significance level alpha of 0.05 .

\section{Results}

\section{Characteristics of participant samples}

The data were collected from 24 participants with dementia in the MCSP group and 23 in the UC group, with mean age MCSP: 78.0 years $( \pm 5.6)$ and UC: $78.4( \pm 7.9)$. Also, 22 carers in the MCSP group and 20 in the UC group were interviewed.

The average MMSE score of participants with dementia in the MCSP group was $20.81( \pm 3.69$, range: $13-27)$ and in the UC group 21.13 ( \pm 3.12 , range: $13-26)$, while the average GDS score in the MCSP group was $3.73( \pm 1.03$, range: $2-5)$ and in the UC group $3.43( \pm 1.28$, range: $1-5)$, which indicates mild-to-moderate dementia. Despite the education level between people with dementia groups, no significant difference between the groups was found. Detailed sociodemographic and clinical data of participants diagnosed with dementia and their carers are presented in Table 1.

\section{Needs and perceived support change between baseline and follow-up within and between groups}

At baseline in people with dementia opinions, there were no statistically significant differences between MCSP and UC groups in the assessment of total ( $P=0.77)$, met $(P=0.38)$, and unmet $(P=0.86)$ needs. Similarly, in the opinion of carers: total $(P=0.88)$, met $(P=0.66)$, and unmet $(P=0.77)$ needs. At baseline, people with dementia from both groups reported the same level of informal support $(P=0.20)$, but there was a significant difference in perceived formal support between MCSP and UC groups $(P<0.01)$ : participant from UC group reported higher level of this form of support (Table 2).

\section{Multivariate general linear model analysis - people with dementia}

Based on the multivariate general linear model with interaction between time and group, changes in experienced needs by people with dementia were observed (Table 3 ). The obtained results indicated that there was a significant

Table I Characteristics of people with dementia from MCSP and UC groups and their carers

\begin{tabular}{|c|c|c|c|c|}
\hline Socio-demographic characteristics & $\begin{array}{l}\text { PwD MCSP } \\
(n=24)\end{array}$ & $\begin{array}{l}\text { PwD UC } \\
(n=23)\end{array}$ & $\begin{array}{l}\text { Carer MCSP } \\
(n=22)\end{array}$ & $\begin{array}{l}\text { Carer UC } \\
(n=20)\end{array}$ \\
\hline \multicolumn{5}{|l|}{$\operatorname{Sex}(n[\% n])$} \\
\hline Male & $7(29.2)$ & $6(26.1)$ & $6(27.3)$ & $7(35)$ \\
\hline Female & $17(70.8)$ & $17(73.9)$ & $16(72.7)$ & $13(65)$ \\
\hline Age (mean \pm SD) & $78.0 \pm 5.6$ & $78.4 \pm 7.9$ & $60.5 \pm 15.1$ & $59.0 \pm 12.7$ \\
\hline \multicolumn{5}{|l|}{ Marital status (n [\%n]) } \\
\hline Married & II (45.8) & $13(56.5)$ & $16(72.7)$ & $14(70.0)$ \\
\hline Widowed & $12(50.0)$ & $10(43.5)$ & - & I (5.0) \\
\hline Single & I (4.2) & - & $3(13.6)$ & $4(20.0)$ \\
\hline Divorced & - & - & $2(9.1)$ & I (5.0) \\
\hline Cohabiting & - & - & I (4.5) & - \\
\hline \multicolumn{5}{|l|}{ Level of qualification (n [\%n]) } \\
\hline Higher education & II (45.8) & $4(17.4)$ & $15(68.2)$ & $13(65.0)$ \\
\hline Vocational level 3 & $10(41.7)$ & $13(56.5)$ & $6(27.3)$ & $6(30.0)$ \\
\hline Vocational level 2 & $\mathrm{I}(4.2)$ & $3(13.1)$ & $\mathrm{I}(4.5)$ & - \\
\hline Qualification at level I and below & $2(8.3)$ & $2(8.7)$ & - & $\mathrm{I}(5.0)$ \\
\hline No qualifications & - & $\mathrm{I}(4.3)$ & - & - \\
\hline \multicolumn{5}{|l|}{ Relationship person-carer (n [\%n]) } \\
\hline Spouse/partner & $9(37.5)$ & $8(34.8)$ & & \\
\hline Child & $10(41.7)$ & $13(56.5)$ & & \\
\hline Siblings & $\mathrm{I}(4.2)$ & - & & \\
\hline Other family relationship & $4(16.6)$ & $2(8.7)$ & & \\
\hline MMSE $($ mean \pm SD) & $20.8 I \pm 3.69$ & $21.13 \pm 3.69$ & & \\
\hline GDS(mean \pm SD) & $3.73 \pm 1.03$ & $3.43 \pm 1.28$ & & \\
\hline
\end{tabular}

Abbreviations: MCSP, Meeting Centres Support Programme; PwD, people with dementia; UC, Usual Care. 
Table 2 Average needs (met and unmet) and the level of support from the people with dementia (MCSP: $n=24 ; U C: n=23)$ and their carers (MCSP: $n=22$; UC: $n=20$ ) perspective at baseline and follow-up (after 6 months)

\begin{tabular}{|c|c|c|c|c|c|c|c|c|}
\hline \multirow[t]{3}{*}{ Needs } & \multicolumn{2}{|c|}{ Baseline follow-up } & \multicolumn{2}{|c|}{ Baseline follow-up } & \multicolumn{2}{|c|}{ Baseline follow-up } & \multicolumn{2}{|c|}{ Baseline follow-up } \\
\hline & PwD MCSP & PwD MCSP & PwD UC & PwD UC & C MCSP & C MCSP & C UC & C UC \\
\hline & \multicolumn{8}{|l|}{$($ mean $\pm S D)$} \\
\hline Total needs & $5.00 \pm 2.83$ & $5.25 \pm 2.02$ & $5.17 \pm 2.71$ & $6.30 \pm 2.58$ & $7.68 \pm 2.34$ & $7.75 \pm 2.42$ & $7.80 \pm 3.24$ & $8.95 \pm 3.42$ \\
\hline Total met needs & $3.37 \pm 1.76$ & $5.05 \pm 1.73$ & $3.96 \pm 2.20$ & $4.80 \pm 1.76$ & $5.27 \pm 2.33$ & $7.70 \pm 2.39$ & $5.55 \pm 2.43$ & $6.42 \pm 2.54$ \\
\hline Total unmet needs & $1.62 \pm 2.10$ & $0.20 \pm 0.52$ & $1.22 \pm 1.35$ & $1.50 \pm 1.47$ & $2.4 I \pm 1.65$ & $0.05 \pm 0.22$ & $2.25 \pm 1.48$ & $2.53 \pm 1.54$ \\
\hline Informal support & $8.96 \pm 6.88$ & $10.00 \pm 5.17$ & $11.87 \pm 8.11$ & $14.75 \pm 8.16$ & $18.04 \pm 7.56$ & $17.01 \pm 7.49$ & $19.65 \pm 10.59$ & $22.37 \pm 10.94$ \\
\hline Formal support & $2.7 \mathrm{I} \pm 2.56^{\mathrm{a}}$ & $7.70 \pm 3.88$ & $4.96 \pm 2.90^{\mathrm{a}}$ & $5.90 \pm 3.97$ & $5.64 \pm 4.98$ & $12.40 \pm 5.83$ & $6.20 \pm 3.59$ & $7.58 \pm 4.48$ \\
\hline
\end{tabular}

Note: asignificant difference in perceived needs and the level of support at baseline between participants with dementia and carers in the MCSP and UC groups.

Abbreviations: C, carers; MCSP, Meeting Centres Support Programme; PwD, people with dementia; UC, Usual Care.

statistical difference between the MCSP and the UC group in total needs perception $(\mathrm{B}=1.47, P=0.0006)$, unmet needs $(\mathrm{B}=1.93, P=0.0001)$, formal support $(\mathrm{B}=-3.92, P<0.0001)$, and informal support $(\mathrm{B}=3.38, P=0.0095)$. However, there was no significant difference between groups in met needs perception in the study period $(\mathrm{B}=-0.65, P=0.20)$.

\section{Total needs and support level - people with dementia}

Analyzing in detail the needs level reported by people with dementia, there was a decrease in the average total unmet needs after 6 months of attending the MCs (1.62 vs 0.20 ) and an increase in the control group (1.22 vs 1.50$)$. The level of informal support (11.87 vs 14.75) increased more among people with dementia from UC group than in the MCSP group (8.96 vs 10.00). Reversely, the level of formal support increased to a greater extent in the MCSP group (2.71 vs 7.70), than in the UC group (4.96 vs 5.90) after the period of 6 months. Detailed data are provided in Table 2.

\section{Multivariate general linear model analysis - carers}

Based on the multivariate general linear model with interaction between time and group, changes in people with dementia needs in opinion of their carers were observed (Table 4). There was a significant difference between the MCSP and the UC group of carers in total $(B=1.29$, $P=0.002)$, met $(\mathrm{B}=-1.49, P=0.007)$, and unmet needs perception (B=2.72, $P<0.0001)$, but also in formal $(\mathrm{B}=-5.23$, $P<0.0001)$ and informal support $(\mathrm{B}=4.38, P=0.003)$.

\section{Total needs and support level - carers}

An increase in total needs level reported by carers of people with dementia was observed in the control group ( $7.80 \mathrm{vs}$ 8.95), with only a slight increase in the MCSP group (7.68 vs 7.75). In should be noted that unmet needs decreased in the opinion of MCSP carers (2.41 vs 0.05 ), but increased in the UC group (2.25 vs 2.53 ). The level of total met needs increased in both carers groups, but more among MCSP

Table 3 Changes in needs experienced by people with dementia (MCSP: $n=24$; UC: $n=23$ ) after 6 months - a multivariate general linear model with interaction between time and group

\begin{tabular}{|c|c|c|c|c|c|c|c|c|c|}
\hline \multirow[t]{2}{*}{ Needs } & \multicolumn{3}{|l|}{ Total } & \multicolumn{3}{|l|}{ Met } & \multicolumn{3}{|c|}{ Unmet } \\
\hline & B & SE & $P$-value & B & SE & $P$-value & B & SE & $P$-value \\
\hline Intercept & 5.00 & 0.53 & $<0.0001$ & 3.37 & 0.38 & $<0.0001$ & 1.62 & 0.31 & $<0.0001$ \\
\hline Time & -0.32 & 0.28 & 0.25 & 1.47 & 0.35 & 0.0002 & $-1.6 \mid$ & 0.31 & $<0.0001$ \\
\hline Control & 0.17 & 0.76 & 0.82 & 0.58 & 0.55 & 0.29 & $-0.4 I$ & 0.44 & 0.36 \\
\hline Interaction & 1.47 & 0.39 & 0.0006 & -0.65 & 0.50 & 0.20 & 1.93 & 0.44 & 0.0001 \\
\hline \multirow[t]{2}{*}{ Support } & \multicolumn{3}{|c|}{ Formal } & \multicolumn{3}{|c|}{ Informal } & & & \\
\hline & B & SE & $P$-value & B & SE & $P$-value & & & \\
\hline Intercept & 2.71 & 0.67 & 0.0002 & 8.96 & 1.48 & $<0.0001$ & & & \\
\hline Time & 4.83 & 0.59 & $<0.0001$ & -0.23 & 0.88 & 0.80 & & & \\
\hline Control & 2.25 & 0.96 & 0.023 & 2.91 & 2.11 & 0.17 & & & \\
\hline Interaction & -3.92 & 0.85 & $<0.0001$ & 3.38 & 1.24 & 0.0095 & & & \\
\hline
\end{tabular}

Abbreviations: B, Spearman-Brown Coefficient; MCSP, Meeting Centres Support Programme; SE, standard error. 
Table 4 Changes in experienced needs from the carers' (MCSP: $n=22 ; \cup C: n=20$ ) perspective after 6 months - a multivariate general linear model with interaction between time and group

\begin{tabular}{|c|c|c|c|c|c|c|c|c|c|}
\hline \multirow[t]{2}{*}{ Needs } & \multicolumn{3}{|l|}{ Total } & \multicolumn{3}{|l|}{ Met } & \multicolumn{3}{|c|}{ Unmet } \\
\hline & B & SE & $P$-value & B & SE & $P$-value & B & SE & $P$-value \\
\hline Intercept & 7.68 & 0.61 & $<0.0001$ & 5.27 & 0.51 & $<0.0001$ & $2.4 \mathrm{I}$ & 0.29 & $<0.0001$ \\
\hline Time & -0.18 & 0.27 & 0.52 & 2.25 & 0.36 & $<0.0001$ & -2.38 & 0.29 & $<0.0001$ \\
\hline Control & 0.25 & 0.87 & 0.77 & 0.34 & 0.74 & 0.65 & -0.12 & 0.42 & 0.77 \\
\hline Interaction & 1.29 & 0.39 & 0.002 & -1.49 & 0.53 & 0.007 & 2.72 & 0.42 & $<0.0001$ \\
\hline \multirow[t]{2}{*}{ Support } & \multicolumn{3}{|c|}{ Formal } & \multicolumn{3}{|c|}{ Informal } & & & \\
\hline & B & SE & $P$-value & B & SE & $P$-value & & & \\
\hline Intercept & 5.64 & 1.02 & $<0.0001$ & 18.04 & 1.95 & $<0.0001$ & & & \\
\hline Time & 6.57 & 0.79 & 0.116 & -1.71 & 0.93 & 0.075 & & & \\
\hline Control & 0.47 & $\mathrm{I} .47$ & 0.749 & 1.93 & 2.79 & 0.49 & & & \\
\hline Interaction & -5.23 & 1.16 & $<0.0001$ & 4.38 & 1.35 & 0.003 & & & \\
\hline
\end{tabular}

Abbreviations: B, Spearman-Brown coefficient; MCSP, Meeting Centres Support Programme; SE, standard error.

(5.27 vs 7.70), than UC participants (5.55 vs 6.42). The level of informal support decreased in the MCSP group (18.04 vs 17.01), but an increase in the UC group was noticed (19.65 vs 22.37). After the period of 6 months, the level of formal support increased in both carers groups, but to a much greater extent in the MCSP group (5.64 vs 12.40), than in the UC group (6.20 vs 7.58) (Table 2).

\section{Differences between groups}

While comparing the differences in the number of total, met, and unmet needs reported between people with dementia and their carers at baseline, it was proven that both in the MCSP and UC groups people with dementia report significantly fewer problems $(P<0.001)$ than carers. A similar observation concerned formal and informal support $(P<0.001)$.

\section{Unmet needs areas change}

At baseline, people with dementia reported most frequently unmet needs in the domains of daytime activities (MCSP $37.5 \%$ and UC 30\%), psychological distress (MCSP 29.2\% and UC 30.4\%), company (MCSP $25 \%$ and UC 30.4\%), and memory (MCSP $20.8 \%$ and UC $17.4 \%$ ), as shown in Table 5. The caregivers reported unmet needs more frequently than people with dementia, but the needs were in the same domains: daytime activities (MCSP $72.7 \%$ and UC 55\%), company (MCSP 54.5\% and UC 55\%), psychological distress (MCSP $45.5 \%$ and UC 45\%), and memory (MCSP $36.4 \%$ and UC $30 \%)$.

Table 5 shows also how unmet needs changed at followup for each of the CANE items. The four most common unmet needs in older people with dementia (daytime activities, psychological distress, company, and memory) were reduced by between $37.5 \%$ and $20.8 \%$ at follow-up in the intervention group. In the control group, an increase between $0 \%$ and $4.4 \%$ in these unmet needs were found, except for the psychological distress-related unmet needs, which increased from $30.3 \%$ at baseline to $45 \%$ at follow-up.

The differences in percentage values presented in Table 5 result from the fact that not all participants answered all questions on the CANE areas.

\section{Discussion}

As far as we know, this is the first study that investigated the (un)met needs of people with mild-to-moderate dementia and their carers before and after implementation of the psychosocial intervention called MCSP in Poland.

The presented study results highlight that based on the opinions of people with dementia and informal carers the unmet needs were reduced considerably in the participants attending the MCs compared to those receiving UC, providing evidence that the participants from the new form of support, MCSP, could be benefited from it with regard to fulfilling unmet needs within an intervention period of only 6 months. Moreover, an increase in formal support both reported by the persons with dementia and their carers was found to a much greater extent in the MCSP, than in the UC groups.

All the studies conducted so far have proven that the provision of care significantly influences the life of a carer to a large extent. This impact includes also the carer's health since they might suffer from depression and physical illness, and also experience lower quality of life. ${ }^{25}$ There is also an increased risk among informal carers of people living with dementia of feeling socially isolated as well as financially 
Table 5 Number of people with dementia (MCSP: $n=24 ;$ UC: $n=23$ ) and carers (MCSP: $n=22$; UC: $n=20$ ) that reported unmet needs for each of the CANE areas at baseline and follow-up (after 6 months)

\begin{tabular}{|c|c|c|c|c|c|c|c|c|}
\hline \multirow[t]{2}{*}{ Unmet needs } & \multicolumn{2}{|l|}{ Baseline (\%) } & \multicolumn{2}{|c|}{ Follow-up (\%) } & \multicolumn{2}{|c|}{ Baseline (\%) } & \multicolumn{2}{|c|}{ Follow-up (\%) } \\
\hline & PwD MCSP & $\begin{array}{l}\text { PwD } \\
\text { UC }\end{array}$ & $\begin{array}{l}\text { PwD } \\
\text { MCSP }\end{array}$ & PwD UC & $\begin{array}{l}\text { Carer } \\
\text { MCSP }\end{array}$ & $\begin{array}{l}\text { Carer } \\
\text { UC }\end{array}$ & $\begin{array}{l}\text { Carer } \\
\text { MCSP }\end{array}$ & $\begin{array}{l}\text { Carer } \\
\text { UC }\end{array}$ \\
\hline Accommodation & $0(0)$ & $0(0)$ & $0(0)$ & $0(0)$ & $0(0)$ & $0(0)$ & $0(0)$ & $0(0)$ \\
\hline Household activities & $0(0)$ & $0(0)$ & $0(0)$ & $0(0)$ & $0(0)$ & $0(0)$ & $0(0)$ & I (5.3) \\
\hline Food & $0(0)$ & $0(0)$ & $0(0)$ & $0(0)$ & $0(0)$ & $0(0)$ & $0(0)$ & $0(0)$ \\
\hline Self-care & $0(0)$ & $0(0)$ & $0(0)$ & $0(0)$ & $0(0)$ & $0(0)$ & $0(0)$ & $0(0)$ \\
\hline Caring for another & $0(0)$ & $0(0)$ & $0(0)$ & $0(0)$ & $0(0)$ & $0(0)$ & $0(0)$ & $0(0)$ \\
\hline Daytime activities $^{\mathrm{a}}$ & $9(37.5)$ & $6(30)$ & $0(0)$ & $6(30)$ & $16(72.7)$ & II (55) & $0(0)$ & II (55) \\
\hline Memory ${ }^{a}$ & $5(20.8)$ & $4(17)$ & $0(0)$ & $3(13)$ & $8(36.4)$ & $6(30)$ & $0(0)$ & $7(36.8)$ \\
\hline Eyesight/hearing & I (4.2) & I (4.3) & I (5) & $3(15)$ & $0(0)$ & $2(10)$ & $0(0)$ & $3(15.8)$ \\
\hline Mobility/falls & $0(0)$ & $0(0)$ & $0(0)$ & I (5) & $0(0)$ & I (5) & $0(0)$ & I (5.3) \\
\hline Incontinence & $0(0)$ & I (4.3) & $0(0)$ & I (5) & $0(0)$ & $0(0)$ & $0(0)$ & $0(0)$ \\
\hline Physical health ${ }^{\mathrm{a}}$ & $3(12.5)$ & $2(8.7)$ & I (5) & I (5) & $\mathrm{I}(4.5)$ & $2(10)$ & $0(0)$ & I (5.3) \\
\hline Drugs & I (4.2) & $0(0)$ & $0(0)$ & $0(0)$ & $\mathrm{I}(4.5)$ & $0(0)$ & $0(0)$ & $0(0)$ \\
\hline Psychotic symptoms & $0(0)$ & $0(0)$ & $0(0)$ & $\mathrm{I}(4.3)$ & I (4.5) & I (5) & $0(0)$ & $0(0)$ \\
\hline Psychological distress ${ }^{a}$ & $7(29.2)$ & $7(30.4)$ & I (5) & $9(45)$ & $10(45.5)$ & $9(45)$ & I (5) & $10(52.6)$ \\
\hline Information on condition & $2(8.3)$ & $0(0)$ & I (5) & I (5) & I (4.5) & $0(0)$ & $0(0)$ & $0(0)$ \\
\hline Deliberate self-harm & $0(0)$ & $0(0)$ & $0(0)$ & $0(0)$ & $0(0)$ & $0(0)$ & $0(0)$ & $0(0)$ \\
\hline Accidental self-harm & $0(0)$ & $0(0)$ & $0(0)$ & $0(0)$ & $0(0)$ & $0(0)$ & $0(0)$ & $0(0)$ \\
\hline Abuse/neglect & $0(0)$ & $0(0)$ & $0(0)$ & $0(0)$ & $0(0)$ & $0(0)$ & $0(0)$ & $0(0)$ \\
\hline Behavior & $0(0)$ & $0(0)$ & $0(0)$ & $0(0)$ & $0(0)$ & $0(0)$ & $0(0)$ & $0(0)$ \\
\hline Alcohol & $0(0)$ & $0(0)$ & $0(0)$ & $0(0)$ & $0(0)$ & $0(0)$ & $0(0)$ & $0(0)$ \\
\hline Company ${ }^{a}$ & $6(25)$ & $7(30.4)$ & $0(0)$ & $6(30)$ & $12(54.5)$ & II (55) & $0(0)$ & $10(52.6)$ \\
\hline Intimate relationships ${ }^{a}$ & $5(20.8)$ & $2(8.7)$ & $0(0)$ & $2(10)$ & $3(13.6)$ & $2(10)$ & $0(0)$ & $3(15.8)$ \\
\hline Managing money & $0(0)$ & $0(0)$ & $0(0)$ & $0(0)$ & $0(0)$ & $0(0)$ & $0(0)$ & $\mathrm{I}(5.3)$ \\
\hline Benefits & $0(0)$ & $0(0)$ & $0(0)$ & $0(0)$ & $0(0)$ & $0(0)$ & $0(0)$ & $0(0)$ \\
\hline
\end{tabular}

Note: aMost common unmet needs at baseline and follow-up in percentage of participants.

Abbreviations: MCSP, Meeting Centres Support Programme; PwD, people with dementia; UC, Usual Care.

burdened. This is especially true for carers who cohabit with the person with dementia since informal carers typically provide them with many hours of care, the number of which frequently increase as the disease progresses. The results of our study indicate that MCSP not only reduces unmet needs of older people with dementia but also, and what is equally important, provides professional formal care during daytime, which makes it possible to relieve informal carers from their burdensome care task.

In terms of needs assessment, there are often discrepancies in perspectives of different assessors. As shown in this study, typically, community-dwelling people with dementia report a significantly lower number of (unmet) needs than their informal carers. ${ }^{26-28}$ The causes of such discrepancy could be as follows: being unaware of difficulties, lacking knowledge regarding the existence of services, barriers to accessing them, and unsatisfactory service offerings. It may be also explained by the willingness to stay autonomous, which is a feeling that makes a person trivialize the assessment of their needs. ${ }^{1}$ Moreover, due to the fact that the person with dementia and the carer often differ in their perspective, there may be many disagreements about the decision-making process that concerns the acceptance of care. Helping people with dementia at an early stage of the disease to gain insight into their needs could help them seek support earlier, but also to develop adaptive coping strategies.

In this study, the domains in which unmet needs most frequently occurred in both participants with dementia MCSP and UC groups are in line with those reported by previous

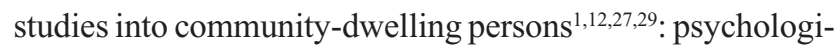
cal distress, daytime activities, memory, and company (psychological and social needs). All the areas of reported unmet needs were almost completely reduced in the MCSP group after the applied intervention, both in the opinion of people 
with dementia and their carers. In the UC control group, the needs level in these areas did not change at follow-up.

The MCSP may, therefore, be seen as a good example of an integrated post-diagnostic psychosocial support for people with mild-to-moderate dementia and their carers. The MCSP might constitute an important part of the post-diagnostic support process, which makes it possible to intervene in a timely manner and to improve the access of people with dementia and dwelling in the community together with their carers to the support and care that is available for them. ${ }^{11}$

\section{Limitations}

There were a few limitations to the study concerning the assessment of the influence of the intervention on people diagnosed with dementia. There was no random allocation to the intervention and the research groups were small. The assessors were aware of the intervention the participants were provided with. The study was limited to the participants of one center, which may not fully reflect the range of needs and the scope of support in other regions or cities in Poland, particularly in smaller towns and rural areas. There were certain limitations to the comparison of our findings with the findings of other authors, which were the result of the differences relating to the choice of the study group.

It cannot be ruled out that the assessment of unmet needs among people with dementia has been biased. Such bias could have been related to such issues as reduced level of attention, concentration, as well as reduced cognitive functions that could make the patient unable to provide information. To address this concern, people with severe dementia were excluded from the analyses. On the other hand, exclusion of individuals with symptoms of severe dementia may potentially influence the results because needs may be expressed differently by subjects with more advanced stages of the condition. In addition, response bias, which is the unconscious influence of the respondent on the anamnesis and the obtained results, cannot be excluded.

\section{Conclusion and future directions}

Meeting physical needs alone is not sufficient to maintain the quality of life of people living with dementia and their carers. It is essential to take a holistic view of the individual and their environment to adequately assess the support needed. These results indicate that the intervention of the MCSP reduced unmet needs after 6 months of participation in the program. Overall, unmet needs reduced in the MCSP group, particularly in the four areas of psychological distress, daytime activities, company, and memory, than in the UC group.
The findings of this study highlight also the importance of a comprehensive needs assessment in community-dwelling elderly people with dementia.

Further dissemination of MCs in Poland may have a multiple impact both on meeting people with dementia's complex needs and on the structure of dementia services.

Further studies of a longitudinal nature and consideration of different perspectives on all areas of CANE needs should focus on a larger group of elderly people with dementia. The other area of investigation could be patterns of needs that remain unmet in elderly people who have been diagnosed with cognitive impairment and dementia. In this way, significant domains of unmet needs, as well as factors that impact the occurrence of unmet needs, may be identified in a reliable and supportive manner.

\section{Acknowledgment}

This is an EU Joint Programme - Neurodegenerative Disease Research (JPND) Project. The project is supported through the following funding organization under the aegis of JPND: Italy, Ministry of Education and Ministry of Health; the Netherlands, ZonMw; Poland, Narodowe Centrum Badań i Rozwoju; and UK, Economic and Social Research Council.

\section{Disclosure}

The authors report no conflicts of interest in this work.

\section{References}

1. Kerpershoek L, de Vugt M, Wolfs C, et al. Needs and quality of life of people with middle-stage dementia and their family carers from the European Actifcare study. When informal care alone may not suffice. Aging Ment Health. 2017;25:1-6.

2. Lee JH, Byun MS, Yi D, et al. Frequency of depressive syndromes in elderly individuals with no cognitive impairment, mild cognitive impairment, and Alzheimer's disease dementia in a memory clinic setting. Dement Geriatr Cogn Disord. 2016;42(3-4):135-145.

3. Huber M, Knottnerus JA, Green L, et al. How should we define health? BMJ. 2011;343:d4163.

4. Vernooij-Dassen M, Jeon YH. Social health and dementia: the power of human capabilities. Int Psychogeriatr. 2016;28(5):701-703.

5. Dröes RM, Chattat R, Diaz A, et al. Social health and dementia: a European consensus on the operationalization of the concept and directions for research and practice. Aging Ment Health. 2017;21(1):4-17.

6. Orrell M, Hancock G, Hoe J, Woods B, Livingston G, Challis D. A cluster randomised controlled trial to reduce the unmet needs of people with dementia living in residential care. Int J Geriatr Psychiatry. 2007; 22(11):1127-1134.

7. Manthorpe J, Samsi K. Person-centered dementia care: current perspectives. Clin Interv Aging. 2016;11:1733-1740.

8. Brodaty H, Green A, Koschera A. Meta-analysis of psychosocial interventions for caregivers of people with dementia. J Am Geriatr Soc. 2003;51(5):657-664.

9. Dröes RM, Meiland FJ, Evans S, et al. Comparison of the adaptive implementation and evaluation of the Meeting Centers Support Program for people with dementia and their family carers in Europe; study protocol of the MEETINGDEM project. BMC Geriatr. 2017;17(1):79. 
10. Smits CH, de Lange J, Dröes RM, Meiland F, Vernooij-Dassen M, Pot AM. Effects of combined intervention programmes for people with dementia living at home and their caregivers: a systematic review. Int J Geriatr Psychiatry. 2007;22(12):1181-1193.

11. Szcześniak D, Dröes RM, Meiland F, et al. Does the community-based combined Meeting Center Support Programme (MCSP) make the pathway to day-care activities easier for people living with dementia? A comparison before and after implementation of MCSP in three European countries. Int Psychogeriatr. 2018;30(11):1717-1734.

12. van der Roest HG, Meiland FJ, Maroccini R, Comijs HC, Jonker C, Dröes RM. Subjective needs of people with dementia: a review of the literature. Int Psychogeriatr. 2007;19(3):559-592.

13. Mazurek J, Szcześniak D, Urbańska K, Dröes R-M, Rymaszewska J. Met and unmet care needs of the elderly with dementia living at home: personal and informal carers' perspectives. Dementia (London). 2017;3(4): 147130121773323.

14. The MEETINGDEM NETWORK: Sharing effective community-based support in dementia [homepage on the Internet]. The Netherlands: MEETINGDEM; 2018. Available from: https://www.meetingdem.eu/. Accessed May 21, 2018.

15. Brooker D, Evans S, Evans S, et al. Evaluation of the implementation of the Meeting Centres Support Program in Italy, Poland, and the UK; exploration of the effects on people with dementia. Int J Geriatr Psychiatry. 2018;33(7):883-892.

16. Dres RM, Breebaart E, Ettema TP, van Tilburg W, Mellenbergh GJ. Effect of integrated family support versus day care only on behavior and mood of patients with dementia. Int Psychogeriatr. 1999;12(1): 99-115.

17. Mangiaracina F, Chattat R, Farina E, et al. Not re-inventing the wheel: the adaptive implementation of the meeting centres support programme in four European countries. Aging Ment Health. 2017;21(1):40-48.

18. Dröes RM, Meiland F, Schmitz M, van Tilburg W. An evaluation of the Meeting Centres Support Programme among persons with dementia and their carers. Nonpharmacol Ther Dement. 2011;2(1): 19-39.
19. Dröes RM, Meiland F, Schmitz M, van Tilburg W. Effect of combined support for people with dementia and carers versus regular day care on behaviour and mood of persons with dementia: results from a multicentre implementation study. Int J Geriatr Psychiatry. 2004;97:1-12.

20. Folstein MF, Folstein SE, McHugh PR. "Mini-mental state". A practical method for grading the cognitive state of patients for the clinician. J Psychiatr Res. 1975;12(3):189-198.

21. Reisberg B, Ferris SH, de Leon MJ, Crook T. The global deterioration scale for assessment of primary degenerative dementia. Am J Psychiatry. 1982;139(9):1136-1139.

22. Reynolds T, Thornicroft G, Abas M. Camberwell Assessment of Need for the Elderly (CANE): development, validity and reliability. Brit $J$ Psychiatr. 2000;176:444-452.

23. Jrymaszewska J, Kłak R, Synak A. CANE - badanie polskiej wersji narzędzia. Psychogeriatria Polska. 2008;5(2):105-113.

24. R Core Team. R: A Language and Environment for Statistical Computing. Vienna, Austria: R Foundation for Statistical Computing; 2017.

25. Etters L, Goodall D, Harrison BE. Caregiver burden among dementia patient caregivers: a review of the literature. J Am Acad Nurse Pract. 2008;20(8):423-428.

26. Stein J, Pabst A, Luck T, et al. Unmet care needs in the oldest old primary care patients with cognitive disorders: results of the AgeCoDe and AgeQualiDe Study. Dement Geriatr Cogn Disord. 2017;44(1-2):71-83.

27. Bakker C, de Vugt ME, van Vliet D, et al. Unmet needs and healthrelated quality of life in young-onset dementia. Am J Geriatr Psychiatry. 2014;22(11):1121-1130.

28. van der Roest HG, Meiland FJ, Comijs HC, et al. What do communitydwelling people with dementia need? A survey of those who are known to care and welfare services. Int Psychogeriatr. 2009;21(5):949-965.

29. Miranda-Castillo C, Woods B, Orrell M. The needs of people with dementia living at home from user, caregiver and professional perspectives: a cross-sectional survey. BMC Health Serv Res. 2013;13(1):43.
Clinical Interventions in Aging

\section{Publish your work in this journal}

Clinical Interventions in Aging is an international, peer-reviewed journal focusing on evidence-based reports on the value or lack thereof of treatments intended to prevent or delay the onset of maladaptive correlates of aging in human beings. This journal is indexed on PubMed Central, MedLine,

\section{Dovepress}

CAS, Scopus and the Elsevier Bibliographic databases. The manuscript management system is completely online and includes a very quick and fair peer-review system, which is all easy to use. Visit http://www.dovepress. com/testimonials.php to read real quotes from published authors. 